\title{
JOGOS PARA O ENSINO DE ARITMÉTICA NO MANUAL A ARITMÉTICA NA ESCOLA NOVA - A NOVA DIDÁTICA DA ARITMÉTICA (1933) DE BACKHEUSER
}

\section{GAMES FOR TEACHING ARITHMETIC IN THE BACKHEUSER'S TEXTBOOK: $A$ ARITHMETIC IN THE NEW SCHOOL- THE NEW DIDATICS OF ARITHMETIC}

(1933)

\author{
SCHNEIDER, Cíntia \\ cintia.schneider@posgrad.ufsc.br \\ UFSC - Universidade Federal de Santa Catarina \\ COSTA, David Antonio \\ david.costa@ufsc.br \\ UFSC - Universidade Federal de Santa Catarina
}

\begin{abstract}
RESUMO O presente artigo tem por objetivo investigar a abordagem de jogos para o ensino de aritmética no manual $A$ aritmética na Escola Nova - a nova didática da aritmética (1933), de Backheuser. Destaca-se o papel dos manuais pedagógicos como fontes de pesquisa, revelando aspectos de uma cultura escolar influenciada por pressupostos escolanovistas naquela época em ascensão no Brasil. Os resultados das análises nesta obra apontam a presença de jogos para o ensino de aritmética embora contraditoriamente o autor explicita seu uso como forma de treinamento e não como meio de despertar o interesse dos alunos.
\end{abstract}

Palavras-chaves: Escola Nova. História da Educação Matemática. Jogos para o ensino de aritmética. Manuais pedagógicos.

ABSTRACT This article aims to investigate the games approach for teaching arithmetic in Backheuser's textbook: Arithmetic in the New School - the new didactics of arithmetic (1933). Noteworthy is the role of teaching manuals as research sources, revealing aspects of a school culture influenced by New School assumptions at that time on the rise in Brazil. The results of the analyzes in this textbook indicate the presence of games for teaching arithmetic though contradictorily the author explains its use as a form of training and not as a means to arouse the interest of students.

Keywords: New School. History of mathematics education. Games for the arithmetic teaching. Textbooks.

\section{CONSIDERAÇÕES INICIAIS}

A investigação na perspectiva histórica vai muito além de compreender determinado tema ou assunto em um dado momento. De fato, é preciso compreender a trama de diversos elementos, como por exemplo, o contexto social, político e econômico da época (VALENTE, 2008).

O presente artigo utiliza um manual pedagógico como fonte de pesquisa em uma perspectiva histórica. Os manuais pedagógicos podem ser chamados de livros 


\section{Atos de Pesquisa em Educação - ISSN 1809-0354 \\ Blumenau, v. 12, n.2, p.406-423, mai./ago. 2017 \\ DOI: http://dx.doi.org/10.7867/1809-0354.2017v12n2p406-423}

didáticos ou ainda livros do professor. Mas independente da sua nomeação, eles fazem parte da chamada cultura escolar. Esta é definida por Julia (2001, p.10) como "[...] um conjunto de normas que definem os saberes a ensinar e os comportamentos a inculcar, e um conjunto de práticas que permitem a transmissão e a assimilação de tais saberes e a incorporação destes comportamentos", sendo esta cultura escolar segundo Viñao Frago (2007) não somente aquilo que se adquire na escola, mas tudo aquilo que não pode ser adquirido em outro lugar que não fosse a escola, além de caracterizá-la como algo que permanece e dura.

O livro ou manual pedagógico em tela é intitulado $A$ aritmética na Escola Nova - a nova didática da Aritmética de Everardo Backheuser, datado do ano de 1933 e publicado pela editora Livraria Católica. O exemplar utilizado na pesquisa faz parte do acervo pessoal de Orlando de Alvarenga Gardio e uma cópia digitalizada deste livro está disponível no Repositório de Conteúdo Digital nas Pesquisas de História da Educação Matemática, que Costa e Valente (2015, p. 99) definem como "[...] um espaço virtual para alocação dos documentos - que se tornarão fontes de pesquisa [...] (o Repositório) torna-se a pedra fundamental que oportuniza e viabiliza o intenso diálogo entre as pesquisas em andamento".

Neste manual, o interesse da investigação está nas indicações de jogos para o ensino de aritmética. Mas aí surge o questionamento: O que é um jogo? Pergunta difícil e ampla de ser respondida: poderia ser um jogo de futebol, um jogo de xadrez, um jogo para crianças, um jogo para adultos, um jogo educativo, um jogo online. Neste sentido que Kishimoto (1999, p. 13) pontua que "Tentar definir o jogo não é tarefa fácil", justificando que "Quando se pronuncia a palavra jogo cada um pode entendê-la de modo diferente".

Além da dificuldade de definir o significado do jogo, há ainda discussões de que sendo o jogo uma atividade livre, espontânea da criança, como torná-lo um objeto para o ensino?

Tomando como base aspectos relacionados ao jogo para o ensino, e mais precisamente para o ensino de aritmética, pretende-se investigar sua presença no manual de Backheuser. Destaca-se que este não foi escolhido de forma aleatória. $\mathrm{Na}$ década de 1930 intensificou-se o movimento da Escola Nova no Brasil, movimento este que Almeida e Silva (2014) definem como: 
Atos de Pesquisa em Educação - ISSN 1809-0354

Blumenau, v. 12, n.2, p.406-423, mai./ago. 2017

DOI: http://dx.doi.org/10.7867/1809-0354.2017v12n2p406-423

[...] pode-se dizer que a Escola Nova ou Movimento Renovador do Ensino, ou, ainda, Pedagogia Nova, entre outras denominações, tem forte influência na Europa, América e no Brasil, neste último mais marcadamente na década de 1930. A criança é colocada no centro do processo de ensino/aprendizagem com metodologias específicas e facilitadoras desse processo, tendo a psicologia e outras ciências como auxiliares, de maneira a opor-se ao ensino dado como tradicional e a romper com a concepção de escola como simples transmissora de conhecimentos (ALMEIDA; SILVA, 2014, p. 61).

Considerando as características deste Movimento, a escolha do manual datado de 1933 foi motivada por que é neste período que estão em ascensão novos métodos de ensino, bem como se passa a estudar a criança em seus aspectos biopsicológicos. Por conta disso, admite-se como hipótese que o jogo esteja entre estes novos métodos propostos e difundidos pelo escolanovismo, possivelmente prescritos nos livros e manuais pedagógicos desta época.

A revisão de literatura apoiada em teses e dissertações apresenta muitos trabalhos que tratam da temática de jogos para ensino de matemática, destacandose as pesquisas de Grando (2000, 2004) e Magalhães (2012).

Ao delimitar a revisão bibliográfica neste tema e que utilizem livros didáticos como fonte de pesquisa, um número expressivo de trabalhos também foi apontado. A dissertação de Campos (2009) trata-se de um dos exemplos que teve por objetivo contribuir para a discussão sobre os jogos e materiais concretos nas coleções de livros didáticos de Matemática das séries iniciais do Ensino Fundamental. Nesta pesquisa, os livros são considerados na sua complexidade, por serem compostos de diferentes dimensões e conotações: cultural, política, econômica, pedagógica, entre outras. Da mesma forma, a dissertação de Trentin (2006) também toma problematiza os jogos e materiais concretos nos livros didáticos de Matemática.

Ainda que muitas pesquisas abordem o tema de jogos para o ensino de matemática e os livros didáticos, nenhuma tratou desse tema em uma perspectiva histórica. Um olhar para as pesquisas em História da Educação Matemática, destaca-se a dissertação de Marques (2013) que analisa manuais didáticos da década de 1930, com a finalidade de investigar as orientações dadas para o ensino de matemática no período de movimento de Escola Nova no Brasil a professores do curso primário. Pontua-se a proximidade com o presente artigo, pois entre as fontes analisadas, a autora se debruça sobre o manual $A$ aritmética na Escola Nova de 


\section{Atos de Pesquisa em Educação - ISSN 1809-0354 \\ Blumenau, v. 12, n.2, p.406-423, mai./ago. 2017 \\ DOI: http://dx.doi.org/10.7867/1809-0354.2017v12n2p406-423}

Everardo Backheuser, apesar do foco não ser os jogos para o ensino de aritmética. Da mesma forma a dissertação De Paula (2015) investiga os manuais didáticos de Aguayo que circularam em Santa Catarina no período de 1942 a 1949.

De fato, a revisão de literatura evidencia uma lacuna de pesquisas que tratam dos jogos para o ensino de aritmética em manuais pedagógicos no período em que estava em ascensão o movimento escolanovismo no Brasil.

Partindo do que foi exposto, este artigo tem o propósito de abordar a indicação de jogos para ensino de aritmética no manual pedagógico $A$ aritmética na Escola Nova - a nova didática da Aritmética de Backheuser em tempos de Escola Nova.

\section{JOGOS PARA O ENSINO DE ARITMÉTICA}

Ao ouvir a palavra jogo, muitas concepções/imagens emergem: talvez de um jogo de futebol ou então xadrez, um jogo coletivo ou então um jogo online. Por conta disso, Kishimoto (1994, p. 2) aponta que "A variedade de fenômenos considerados como jogo mostra a complexidade da tarefa de defini-lo".

Diante da dificuldade em definir o conceito de jogo em um termo universal, Kishimoto em suas obras 'O jogo e a educação infantil' (1994), 'Jogo, Brinquedo, brincadeira e a educação' (1999) e 'O brincar e as teorias' (2002), aponta características dos jogos citadas por outros autores importantes na área, como Caiilois (1967, apud KISHIMOTO, 1994, 1999, 2002), Huizinga (1951, apud KISHIMOTO, 1994, 1999, 2002), Henriot (1989, apud KISHIMOTO, 1994, 1999, 2002). Por exemplo, Huizinga (1951, apud KISHIMOTO, 1994, 1999, 2002), que defende o jogo "[...] como atividade voluntária do ser humano. Se imposta, deixa de ser jogo" (KISHIMOTO, 1999, p. 24), além de defender que ao brincar a criança entra em um mundo imaginário, aponta o caráter "não-sério" da ação e define as regras como característica dos jogos.

Kishimoto $(1994,1999,2002)$ cita como características do jogo defendida por Caillois, a presença constante da incerteza, a existência das regras, a liberdade de ação de quem está jogando, a intenção lúdica. Este autor ainda é conciso em afirmar que o jogo tem caráter improdutivo, no sentido de que a criança ao jogar não objetiva atingir um produto final, o que lhe interessa é a diversão e não 


\section{Atos de Pesquisa em Educação - ISSN 1809-0354 \\ Blumenau, v. 12, n.2, p.406-423, mai./ago. 2017 \\ DOI: http://dx.doi.org/10.7867/1809-0354.2017v12n2p406-423}

conhecimento, além de que em um jogo nunca se tem conhecimentos prévios sobre os rumos que o jogo irá ter, podendo assim incluir a incerteza como uma das suas características.

Percebe-se que esses dois autores, Huizinga (1951, apud KISHIMOTO, 1994, 1999, 2002) e Caillois (1967, apud KISHIMOTO, 1994, 1999, 2002), ambos historiadores, convergem em muitos pontos ao caracterizar os jogos. E "São tais características que permitem identificar fenômenos que pertencem à grande família dos jogos" (KISHIMOTO, 1999, p. 27).

Já Henriot (1989, apud KISHIMOTO, 1994, 1999, 2002), antropólogo, defende que "[...] para se ter a dimensão completa do jogo, é preciso analisar dois elementos: a situação concreta, observável, compreendida como jogo e, a atitude mental do sujeito, envolvido na atividade" (KISHIMOTO, 1999, p. 5).

Brougére, também antropólogo que se dedicou ao estudo do brinquedo, da cultura e da criança, defende que "Pode-se então considerar que através do jogo, a criança faz a experiência do processo cultural, da interação simbólica em toda sua complexidade" (BROUGÉRE, 2002, p. 32).

Exatamente por conta dos jogos se situarem em uma categoria ampla e de difícil definição, é que suas características/propriedades foram estudadas por historiadores, antropólogos, linguistas, psicólogos e educadores. Dentre os psicólogos destaca-se Piaget, importante nome do construtivismo e pioneiro nos estudos sobre o desenvolvimento infantil, integrando aspectos cognitivos, morais e sociais da criança e que ao trabalhar os seis conceitos piagetianos básicos e definir os estágios de desenvolvimento da inteligência (sensório motor; pré-operacional; operações concretas e operações formais), inclui os jogos em suas discussões.

Elkind (1978) pontua que para Piaget é preciso que os pais entendam que fazer com que uma criança aprenda algum conteúdo contra sua vontade pode ter efeitos indesejáveis, como a aversão a escola e a aprendizagem. Ainda, são apontados dois equívocos sobre o aprendizado das crianças pequenas:

Um dos mais graves e perniciosos equívocos sobre crianças pequenas é que elas se assemelham imensamente aos adultos em seu pensamento e se parecem pouquíssimo conosco em seus sentimentos. De fato, o inverso é que é verdadeiro: as crianças são muito parecidas conosco em seus sentimentos e pouco em seu modo de pensar. Um segundo equívoco sobre crianças pequenas é que elas aprendem melhor enquanto estão sentadas e quietas, escutando o que lhes é dito. A causa desse equívoco é que os pais 


\section{Atos de Pesquisa em Educação - ISSN 1809-0354 \\ Blumenau, v. 12, n.2, p.406-423, mai./ago. 2017 \\ DOI: http://dx.doi.org/10.7867/1809-0354.2017v12n2p406-423}

tendem a generalizar a partir de sua experiência de adultos. É certamente verdade que, como adultos, aprendemos amiúde enquanto escutamos em silêncio um conferencista ou lemos um livro. Mas isso não significa que sejamos aprendizes passivos. Ouvir e ler atentamente envolve muita atividade, mas é mental, não física. As crianças pequenas não são capazes de atividade mental ou pensamento de maneira idêntica à adulta (ELKIND, 1978, p. 62-63).

Esse autor ainda complementa que o aprendizado das crianças deve ocorrer por meio de ações reais, manipulando materiais. Tanto Piaget quanto Montessori concordam que é no jogo que a criança internaliza ações como pensamento. $E$ diferente do que muitos adultos pensam, uma criança sentada e em silêncio pode até aprender, mas esse aprendizado, possivelmente, será simplesmente decorado, enquanto ao manipularem materiais, como ocorre em jogos, as crianças estarão desenvolvendo sua capacidade de pensar (ELKIND, 1978).

O jogo torna-se educativo quando há equilíbrio entre o brincar e o ensinar, em que deve haver a orientação e acompanhamento de um professor. Apesar de muitos estudiosos como Huizinga, por exemplo, apontarem que o jogo não deve ser imposto, quando este jogo tem o objetivo educativo, ele deve ser imposto, mas considerando o interesse da criança, buscando desenvolver a ludicidade.

Educadores como Alan e Chanteau também apresentam justificativas para se utilizar os jogos nas escolas, o chamado o jogo educativo. Alan defende o uso de jogos educativos com vistas que seu uso estimula a exploração, favorece o aprendizado pelo erro e a solução de problemas, além de que o jogo cria um ambiente livre de constrangimentos quando o aluno erra (KISHIMOTO, 1999). Kamii (1990, p. 59) corrobora a ideia, destacando a relevância do desenvolvimento de jogos em grupo, no sentido de que eles "[...] são situações ideais para a troca de opiniões entre crianças. Neles as crianças são motivadas a controlar a contagem e a adição dos outros, para serem capazes de se confrontar com aqueles que trapaceiam ou erram".

Chanteau, assim como Alan também defende o uso de jogos na educação, justificando que estes desenvolvem o aprendizado moral, integram as crianças e além disso, vê positivamente o uso das regras. Ainda defende que o jogo na educação prepara a criança para a vida adulta, apesar de alertar que a educação não se deve basear exclusivamente nos jogos, pois isso poderia inserir a criança em um mundo ilusório (KISHIMOTO, 1999). 
Atos de Pesquisa em Educação - ISSN 1809-0354

Blumenau, v. 12, n.2, p.406-423, mai./ago. 2017

DOI: http://dx.doi.org/10.7867/1809-0354.2017v12n2p406-423

Ao tratar da discussão de jogos, não se poderia deixar de citar contribuições do linguista sócio-interacionista Lev Vygotski, que vê o jogo como uma atividade social, em que a criança recria a realidade (VYGOTSKI, 1988). Cerisara (2002, p. 126), em seu estudo sobre Vygostski complementa que "[...] a imaginação não cria nada que não seja tomado da experiência vivida. Ou seja, a base da criação é a realidade".

É importante destacar que apesar de se afirmar o uso de jogos por crianças, Kishimoto (1999) adverte que:

Psicólogos tem dado grande atenção ao papel do jogo na constituição das representações mentais e seus efeitos no desenvolvimento da criança, especialmente da faixa de 0 a 6 anos de idade. Muitos estudos de natureza metafórica explicitam, também, jogos para crianças de outras faixas etárias. Por envolver relações abstratas, analogias, jogos matemáticos e físicos que fazem comparações metafóricas são adequados, geralmente, para crianças com mais idade (KISHIMOTO, 1999, p. 9).

Após esta revisão das características dos jogos apontadas por historiadores, psicólogos, educadores e antropólogos acentua-se a relevância dos jogos para o desenvolvimento infantil, fora do ambiente escolar, bem como dentro das escolas.

\section{O MANUAL PEDAGÓGICO A ARITMÉTICA DA ESCOLA NOVA - A NOVA DIDÁTICA DA ARITMÉTICA E OS JOGOS PARA ENSINO DE ARITMÉTICA}

Apesar de usar-se, usualmente, livros didáticos e manuais pedagógicos como sinônimos, Choppin (2002) define os manuais pedagógicos como ferramentas destinadas a facilitar a aprendizagem e servem como suporte ao ensino. Sua importância repousa na difusão e uniformidade do discurso, pois além da prescrição de um programa, os manuais, no caso os pedagógicos, participam da construção de uma identidade profissional, de um sistema de valores que diz respeito à profissão, à educação, aos saberes a serem ensinados, principalmente sobre a melhor forma de ensiná-los (CHOPPIN, 2002). Consideramos neste artigo que o livro em análise se caracteriza como um manual pedagógico, visto que era destinado aos professores.

Everardo Adolpho Backheuser, o autor do manual pedagógico se destacou na literatura brasileira. Era engenheiro, geógrafo e pedagogo, além de representante católico, preocupado com a nacionalização do ensino primário e estudioso da Escola Nova, principalmente no que diz respeito ao papel do professor e aritmética na 


\title{
Atos de Pesquisa em Educação - ISSN 1809-0354 \\ Blumenau, v. 12, n.2, p.406-423, mai./ago. 2017 \\ DOI: http://dx.doi.org/10.7867/1809-0354.2017v12n2p406-423
}

escola primária (PINTO, 2016). Backheuser se tornou um importante nome na luta entre católicos e liberais pela hegemonia do comando na educação brasileira:

\begin{abstract}
Levando em conta que Everardo Backheuser era um representante atuante na defesa do ensino religioso e temia as mudanças que a pedagogia escolanovista poderia causar, torna-se tema importante o estudo da estratégia utilizada pelo autor ao escrever um manual para o ensino de aritmética direcionado para professores primários em um período de efervescência do movimento da Escola Nova no Brasil. Destaque-se que seu manual fez parte do programa de ensino do Instituto de Educação do Rio de Janeiro juntamente com outros manuais pedagógicos destinados para o ensino de aritmética (MARQUES, 2013, p. 81).
\end{abstract}

Marques (2013) ressalta que, no início do século $X X$, motivado pela necessidade de definição das finalidades do escolanovismo, coube ao Ministério da Educação brasileiro criar meios de discutir seus princípios, como por exemplo, o incentivo ao uso de manuais pedagógicos com vistas a difundir tais finalidades. A autora cita o manual de Backheuser como um destes meios criados para difundir as intenções do Movimento da Escola Nova, pontuando assim, a importância desse manual.

De forma geral, Marques (2013, p. 86) defende que as orientações referentes "[...] a prática para o ensino de matemática lidos no manual do autor Backheuser (1933), ao que tudo indica, utilizava a tática de tentar modernizar o ensino intuitivo, considerando muitas ideias que circularam do ideário da escola nova”, evidenciando a relevância deste material na difusão dos princípios escolanovistas.

No período do movimento da Escola Nova no Brasil, os autores de manuais pedagógicos, mediante ao contexto de reformas educacionais, se apropriaram de ideias escolanovistas. Usavam de estratégias para defender as suas ideias, fazendo-as circular por meio de seus manuais pedagógicos, orientando os professores para práticas de ensino consideradas ideais, de acordo com seus reais interesses e convicções. A intenção dos autores era moldar o docente ideal de acordo com seus propósitos pedagógicos, políticos e/ou filosóficos (MARQUES, 2013, p. 39-40).

O manual pedagógico $A$ aritmética na Escola Nova - a nova didática da Aritmética, de autoria de Everardo Adolpho Backheuser, é datada do ano de 1933 e publicado pela Editora Livraria Católica do Rio de Janeiro. O manual é dividido em sete partes que versam sobre a "A didática da aritmética à luz da psicologia", "Variação da psicologia infantil a partir da idade" "Fim do período escolar primário", "O ensino de aritmética no Brasil", "Fatores primordiais da didática matemática", 


\title{
Atos de Pesquisa em Educação - ISSN 1809-0354 \\ Blumenau, v. 12, n.2, p.406-423, mai./ago. 2017 \\ DOI: http://dx.doi.org/10.7867/1809-0354.2017v12n2p406-423
}

"Sugestões práticas" e "Cálculo mental". Nos títulos dados a cada parte do livro, pode-se perceber a influência dos princípios da Escola Nova, notadamente pela intensa presença das palavras alusivas a psicologia. Monarcha reforça a questão da psicologia na Escola Nova e ainda cita outros campos as quais são utilizados para compreender a criança:

\begin{abstract}
Com a incorporação dos conhecimentos originários da psicologia de base biológica e fisiológica e da estatística, almejava-se melhor caracterização da infância (e consequentemente do adulto); ao se estabelecerem as constantes do desenvolvimento, os estágios de maturação e a identificação das diferenças individuais, almejava-se renovar as técnicas de ensino; e, por fim, com a incorporação da explicação sociológica, firmava-se a tese da influência da sociedade na formação dos sentimentos e da personalidade humana. Em suma, o alvo privilegiado era o estudo do comportamento humano (MONARCHA, 2009, p. 60).
\end{abstract}

Logo nas primeiras páginas do manual são referenciadas outras obras de autoria de Backheuser e há uma descrição de quem foi o autor: professor catedrático da Escola Politécnica, membro da Academia Brasileira de Ciências, cofundador da Associação Brasileira de Educação, presidente da Associação de Professores Católicos do Distrito Federal e do Estado do Rio de Janeiro.

Nas páginas iniciais do manual, Backheuser (1933, p. 9) cita que "Quem quer que indague o que se passa em uma escola primária ou secundária, há de ouvir que a matemática é em geral, considerada a matéria mais difícil", justificando tal situação por vários motivos: poderia ser por que para aprender matemática é preciso ter talentos, ou então, talvez seja proveniente das características da disciplina: precisa, rigorosa. Por fim, questiona-se se não seria decorrente da metodologia utilizada que ocorra tais situações.

Como resposta a estas proposições, Backheuser (1933, p. 11) cita que "O melhor meio de responder a estas perguntas é, ao nosso ver, pôr o problema em equação á luz das ciências fundamentais da psicologia, que mais de perto dá diretrizes à didática das disciplinas". Sendo assim, já nesta parte introdutória do manual, o autor deixa claro sua posição a favor de princípios escolanovistas, em que a psicologia e a didática passam a ser elementos fundamentais na compreensão do como ensinar e como aprender.

De forma sucinta, seguem descritos alguns pontos dos capítulos do livro, com foco principal no tópico destinado aos jogos. 


\section{Atos de Pesquisa em Educação - ISSN 1809-0354 \\ Blumenau, v. 12, n.2, p.406-423, mai./ago. 2017 \\ DOI: http://dx.doi.org/10.7867/1809-0354.2017v12n2p406-423}

No primeiro capítulo nomeado 'Didática da aritmética à luz da psicologia', o autor inicia afirmando "Que a psicologia é um dos pontos de apoio da pedagogia, sabem-no todos" (BACHKEUSER, 1933, p. 13) assim como a sociologia também é uma "[...] viga mestre da pedagogia" (BACHKEUSER, 1933, p. 14). Como terceiro ponto ainda é destacada a filosofia como relevante na pedagogia. Estes três pontos de apoio psicologia, sociologia e filosofia - "[...] se harmonizam para dar valor e importância à aritmética desde o ensino primário" (BACHKEUSER, 1933, p. 15). A atenção dada a estes três pontos é fundamentada nos princípios escolanovistas, em que:

[...] renovação pedagógica revelou-se fundamental para o ensino e passou a ser difundido com o intuito de buscar novas concepções de ensino, em consoante com o desenvolvimento das correntes biológicas, sociológicas e psicológicas da época, de um modo que viria influenciar diversas reformas no ensino desenvolvidas no final dessa década. O que se sabe é que esses movimentos vem modificar os currículos escolares, que aos poucos vão se adaptando as novas realidades, modificando o curso das disciplinas (FERNANDES; BORGES, 2015, p. 195).

No capítulo 'Variação da Psicologia Infantil com a Idade' o autor defende a importância de o professor estar atento aos diferentes tipos psicológicos de uma criança em período escolar. Backheuser (1933) categoriza os estágios de evolução da criança, sendo a primeira fase, denominada a síntese da fantasia, período em que os detalhes são desprezados. Nesta fase as crianças conversam com bonecas e ainda o espírito crítico encontra-se em uma fase embrionária, levando a criança a aceitar o que lhe for dito. A segunda fase é chamada de análise, que inicia por volta dos 9 anos e é caracterizada pelo início do desenvolvimento do espírito crítico e por fim, a terceira fase, que seria o segundo período de síntese, que ocorre na puberdade, em que a exatidão e observação de detalhes é desenvolvida.

Backheuser (1933) especifica como ensinar as crianças, apontando que durante o primeiro período, em que a criança está com no máximo 9 anos, o ensino - não somente de aritmética - deveria seguir algumas diretrizes, compostas por quatro itens: o ensino em conjunto ou global; o ensino por meio de jogos; o ensino intuitivo; e o ensino de "autoridade".

O ensino global refere-se a um ensino coordenado de todas as disciplinas, já o ensino intuitivo e concreto tem sua relevância justificada pelos alunos nesta idade (inferior a 9 anos) serem predominantemente visuais. Sobre o ensino de autoridade, 


\section{Atos de Pesquisa em Educação - ISSN 1809-0354 \\ Blumenau, v. 12, n.2, p.406-423, mai./ago. 2017 \\ DOI: http://dx.doi.org/10.7867/1809-0354.2017v12n2p406-423}

o autor é enfático ao dizer que nesta fase as crianças aceitam tudo, por conta disso não esboçam suas opiniões. Backheuser (1933) destaca que esta questão de autoridade causa a inferioridade das crianças e esta inferioridade só pode ser superada com o uso de jogos.

Se em todas as disciplinas isto é uma verdade geral - maiormente em aritmética. As dificuldades que a aritmética oferece para certos tipos psicológicos desaparecerão talvez sob a pressão de um esclarecimento enunciado de modo decisivo, principalmente quando estiver o campo mental infantil preparado por noções adquiridas pelo método intuitivo e com auxílio de jogos (BACKHEUSER, 1933, p.63).

Vista a relevância dos jogos para a superação da inferioridade da criança, destaca-se a segunda diretriz para o ensino de crianças: $O$ ensino por meio de jogos. Os jogos são definidos por Backheuser (1933, p. 55) como "[...] uma conquista pacífica da pedagogia, pois que o jogo é como que a síntese da fantasia da realidade".

Ao falar da relevância dos jogos, o autor transparece sua defesa pelo uso, porém pontua que até mesmo escolas que afirmam seguir princípios escolanovistas não os utilizam de forma adequada:

\footnotetext{
Não importa, pois, investigarmos a causa, ou a teoria, basta o fato; e este é de que o jogo é de grande valor pedagógico. Para todo e qualquer ensino. Para o ensino de aritmética em particular. Todavia, não o vemos ainda aplicado de modo generalizado nas nossas escolas, nem os jogos em geral, nem os jogos de matemática. Até mesmo nos estabelecimentos que se ufanam de querer aplicar a "escola nova" faltam eles, o ou pelo menos não há com abundância recomendável (BACKHEUSER, 1933, p.55)
}

Bachkeuser (1933) critica as escolas que dizem aplicar os princípios da Escola Nova e que não utilizam os jogos de forma adequadas. Souza (2016) discorre sobre as indicações escolanovistas para o uso de jogos e o princípio do desenvolvimento da autonomia e da importância das atividades espontâneas das crianças. A pesquisadora afirma que "Os jogos aparecem, nesse contexto, como estratégias para estimular o interesse e a participação das crianças nos processos educativos" (SOUZA, 2016, p. 150), além de citar nomes como Decroly, Claparèd e Montessori como elaboradores de atividades de aprendizagem. Neste sentido, destaca-se as ideias de Lourenço Filho (1978, p. 150) de que ao fazer-se uso de atividades lúdicas no processo de aprendizagem a criança geralmente vai "[...] do 


\section{Atos de Pesquisa em Educação - ISSN 1809-0354 \\ Blumenau, v. 12, n.2, p.406-423, mai./ago. 2017 \\ DOI: http://dx.doi.org/10.7867/1809-0354.2017v12n2p406-423}

jogo primitivo às formas do jogo superior e do trabalho com fim intrínseco" justificando o local dos jogos nos princípios da Escola Nova.

Para Backheuser (1933) os jogos podem seguir muitos objetivos, a qual o autor cita alguns jogos, como por exemplo o relógio, os dados, jogo da glória ${ }^{1}$ são caracterizados como jogos que agradam as crianças. É aconselhado o uso do baralho também, desde que seja explorado seu lado educativo, bem como o dominó é destacado como um jogo interessante, em que podem ser exploradas as operações básicas.

Além destes jogos que utilizam materiais, é citado o jogo de feira-livre, em que o aluno é aproximado de situações cotidianas. Este jogo pertence à categoria dos chamados jogos de movimentação, que despertam interesse 'fora do comum' dos alunos. Este tipo de jogo pode ser, facilmente interligado com o preceito da escola nova de que as escolas deveriam se organizar como "[...] um pequenino mundo real, prático, que pusesse o aluno tanto quanto possível, em contato com a natureza e a realidade das coisas" (LOURENÇO FILHO, 1978, p. 160).

Além destes jogos, o manual de Backheuser destaca a importância de os alunos produzirem seus próprios jogos, apesar de lamentar que estas produções dificilmente são realizadas. Dentre estes jogos destacam o jogo do bonde elétrico, caracterizado por ser de fácil aplicação. Este consistia em imaginar a sala como um bonde e desenhar um grande relógio no quadro que marcava as passagens cobradas, e sobre esta atividade eram resolvidos cálculos e problemas matemáticos. Para finalizar o tópico sobre os jogos, Backheuser é pontual em afirmar que a importância dos jogos é proveniente dos princípios escolanovistas ainda que:

Precisando ter a educação um caráter fundamentalmente social, cumpre dar aos alunos o ensejo de mutuo auxílio, como, mais tarde, há de suceder na vida quotidiana. Os jogos coletivos prestam-se extraordinariamente ao desenvolvimento não só da sociabilidade como da solidariedade. Aproveitando sempre as oportunidades que o ensino de conjunto favorece, o professor saberá dar tonalidades matemáticas ao mesmo, valendo-se do que indicarem as leituras dos livros e revistas técnicas, a sua experiência e as sugestões, em regras felizes, da própria classe (BACHKEUSER, 1933, p. 58-59).

\footnotetext{
${ }^{1}$ Também é conhecido como Jogo do Ganso. É um jogo de tabuleiro, com 63 casas, em que cada jogador lança os dados e avança o número de casas correspondente.
} 


\section{Atos de Pesquisa em Educação - ISSN 1809-0354 \\ Blumenau, v. 12, n.2, p.406-423, mai./ago. 2017 \\ DOI: http://dx.doi.org/10.7867/1809-0354.2017v12n2p406-423}

Este tópico evidencia a importância de se trabalhar com os jogos, no sentido de promover a aprendizagem, bem como desenvolver nos alunos espíritos de solidariedade e sociabilidade, além de permitir que o aluno aprenda com atividades próximas do seu cotidiano, podendo aplicar com facilidade conceitos aprendidos em sala de aula em sua vida diária. Ressalta-se novamente que estas características são apontadas como relevantes no Movimento da Escola Nova.

No tópico sobre o fim do período escolar primário, o autor destaca que o ensino deve se dar da mesma forma que era feito para com as crianças de até 9 anos, utilizando-se do ensino do conjunto, ensino intuitivo, ensino de autoridade e inclusive com os jogos, ressaltando que se considere a faixa etária do aluno e que se adapte as atividades/jogos propostos. Destaca-se que o ensino deve gradualmente ir mudando de intuitivo para dedutivo, bem como os jogos devem ocorrer com menor frequência na medida que o ensino se torna cada vez mais especializado, bem com a autoridade do professor irá diminuindo na medida que os alunos vão colaborando cada vez mais.

No tópico referente ao ensino de Aritmética no Brasil, expõem-se que seguiram-se adaptações de outros modelos advindos do exterior, sendo que o ensino evoluiu lentamente e teve influência de três fases: a influência francesa, a mais antiga, em que a educação matemática era baseada predominantemente na memória; influência positivista, a didática era baseada no raciocínio, e por fim a influência norte-americana, destacando-se a prática, contemporânea a época do manual (1933).

No subtítulo 'Os fatores primordiais da didática da aritmética', Backheuser (1933) cita o raciocínio, a memória e o aspecto utilitário/preparo para vida, destacando que o ideal é que haja um equilíbrio entre estas formas pedagógicas.

O tópico destinado as 'Atividades sugeridas' é exposto nas considerações feitas por Pinto (2016, p. 182) como "[...] organizado a partir dos pressupostos teóricos defendidos no livro, como o caráter prático, entendido como utilidade na vida do aluno". Para isso, são sugeridas inúmeras atividades que utilizam de materiais concretos, que considerem o interesse do aluno, atendendo sempre a adequação as diferenças dos alunos, citando diferentes formas de se trabalhar com alunos mais teóricos, mais visuais ou então auditivos. 
Atos de Pesquisa em Educação - ISSN 1809-0354

Blumenau, v. 12, n.2, p.406-423, mai./ago. 2017

DOI: http://dx.doi.org/10.7867/1809-0354.2017v12n2p406-423

Destaca-se neste tópico, o subitem de jogos, em que são indicados de forma mais direta atividades com materiais como o dado, em que pode-se trabalhar com operações básicas, principalmente com a adição. Nesta parte da obra, sugere-se que os dados podem ser construídos pelos alunos. Já o dominó é definido como o que "[...] presta serviços mais relevantes que o dado. Facilita a aprendizagem de contas de somar mais variadas. O dominó é, pois, dos jogos um dos mais aconselháveis" (BACHKEUSER, 1933, p. 117), que também pode ser usado em outras disciplinas escolares. O jogo da glória é definido como um jogo variado, em que podem ser trabalhadas todas as operações aritméticas, bem como é um jogo de fácil adaptação. Já o baralho é dito como um jogo importante em aritmética, porém é preciso ter cuidado, visto sua ligação com jogos de azar. Para encerrar o tópico de atividades sugeridas de jogos, Bachkeuser expõem a regra geral para o uso de qualquer jogo:

[...] é servirem principalmente para exercício e só, excepcionalmente para aquisições propriamente ditas de aritmética. $O$ jogo deve ficar no nível mental do aluno, quando muito ligeiramente acima, mas normalmente um pouco abaixo, de maneira a se prestar para treino (BACHKEUSER, 1933, p. 188).

Com isso, destaco contrariamente ao exposto no tópico 'Os jogos para ensino de aritmética', nos quais há discursos de que os jogos possuem a função de tornar o aluno um ser autônomo, que saiba competir, saiba trabalhar em grupos, o que se constata nas indicações do manual analisado (1933) são os jogos sendo tratados como forma de treino.

Ainda que o movimento da Escola Nova se apresente como forma de superação do ensino tradicional, as últimas ideias de Backheuser enfatizam o uso dos jogos como forma do aluno treinar, 'decorar' e não como meio de fazer o aluno pensar.

O último capítulo refere-se ao cálculo mental em que este é aconselhável, recomendável e exigível. O cálculo mental é tratado como mutuamente auxiliador do cálculo escrito, não diminuindo nenhum destes. Sendo que o cálculo mental permite segurança e rapidez nas operações. São apresentadas formas de desenvolvimento do cálculo mental com as operações aritméticas.

\section{CONSIDERAÇÕES FINAIS}




\section{Atos de Pesquisa em Educação - ISSN 1809-0354 \\ Blumenau, v. 12, n.2, p.406-423, mai./ago. 2017 \\ DOI: http://dx.doi.org/10.7867/1809-0354.2017v12n2p406-423}

Este artigo teve como intuito investigar como os jogos para ensino de aritmética estão abordados no manual pedagógico de autoria de Everardo Backheuser. Para contribuir nas análises, foram apresentadas algumas outras ideias sobre o que é um jogo, segundo outros educadores, psicólogos, antropólogos.

Pela revisão bibliográfica constatou-se que há um número expressivo de trabalhos que tratam dos jogos para ensino de matemática, bem como tantos outros que os investigam em livros didáticos. No entanto, há lacunas sobre as investigações que tomam o jogo para o ensino de aritmética em livros didáticos na perspectiva histórica.

Para a análise do manual $A$ aritmética da Escola Nova - a nova didática da aritmética, explanou-se, de forma breve, que o autor Backheuser, engenheiro, geógrafo, pedagogo e representante católico se destacou na literatura brasileira por ter preocupação com a nacionalização do ensino primário, além de ser um estudioso da Escola Nova.

No manual analisado encontra-se um tópico destinado exclusivamente ao 'ensino por meio de jogos', em que é citada a relevância de se ensinar com o auxílio de jogos. Enfatiza-se tal ideia exemplificando jogos que utilizem materiais como o dado, o baralho, ressaltando a importância dos alunos produzirem seus próprios jogos, mas ao mesmo tempo lamentando por esta ser uma prática pouco presente nas escolas daquela época. Ainda são recomendados jogos que imitem situações cotidianas dos alunos, como por exemplo uma feira. Ao fim deste tópico, Backheuser destaca que com o uso dos jogos pode-se desenvolver a sociabilidade e a solidariedade dos alunos, além de favorecer a percepção da aritmética em situações cotidianas.

O que se infere até então é a estreita relação das indicações destes jogos com os fundamentos da Escola Nova. Nesta perspectiva, a escola deve ser vista como uma pequena sociedade e que se devem tratar assuntos ou situações presentes no cotidiano do aluno.

Ainda os jogos são tratados no item 'atividades propostas', em que são sugeridas atividades que utilizam materiais concretos, considerando o interesse e a adequação dos jogos aos alunos. São indicados jogos tais como o dado relacionando conceitos da adição, ou ainda jogos como o dominó que também 
Atos de Pesquisa em Educação - ISSN 1809-0354

Blumenau, v. 12, n.2, p.406-423, mai./ago. 2017

DOI: http://dx.doi.org/10.7867/1809-0354.2017v12n2p406-423

favorecem o desenvolvimento de conhecimentos aritméticos. Ainda, destaca-se o jogo da glória, que consiste em um jogo de tabuleiro e o baralho, que apesar de importante deve-se tomar cuidado para não exaltar sua ligação com jogos de azar.

De modo geral, nas atividades sugeridas, o autor expõe uma regra para o uso de qualquer jogo, em que estes devem ter a função, principalmente, de exercícios, como uma forma de treino. A partir dessa situação, pode-se inferir que apesar dos princípios escolanovistas terem o intuito de superar o ensino tradicional, de fato Backheuser demonstra uma posição conservadora. As indicações dos jogos no seu manual revelam aspectos de natureza de treinamento, isto é, os usos dos mesmos favorecem o aluno 'decorar' regras: os jogos, nesta perspectiva, não servem como meio de despertar o interesse dos alunos ou ainda de desenvolver formas de ensino distintas do ensino tradicional.

Por fim, a análise deste manual permitiu estabelecer sua estreita ligação com os preceitos escolanovistas, além de constatar que já na década de 1930 houve o alinhamento da circulação de manuais pedagógicos que buscavam difundir o uso de jogos para o ensino de aritmética.

\section{CINTIA SCHNEIDER}

Licenciada em Matemática pelo Instituto Federal Catarinense. Mestranda do Programa de Pós-Graduação em Educação Científica e Tecnológica da Universidade Federal de Santa Catarina. Pesquisadora do GHEMAT - Grupo de Pesquisa de História da Educação Matemática.

\section{DAVID ANTONIO COSTA}

Doutor em Educação Matemática pela PUC/SP. Professor Adjunto III do Departamento de Metodologia de Ensino do Centro de Ciências da Educação. Professor do Programa de Pós-Graduação em Educação Científica e Tecnológica da Universidade Federal de Santa Catarina. Pesquisador do GHEMAT - Grupo de Pesquisa de História da Educação Matemática.

\section{REFERÊNCIAS}

ALMEIDA, D. H. de; SILVA, M. C. L. de. Resolução de problemas na formação de professores primários em tempos de Escola Nova. Revista Acta Scientiae, CanoasRS, v.16, n.1, p.57-71, jan/abr. 2014. 


\section{Atos de Pesquisa em Educação - ISSN 1809-0354 \\ Blumenau, v. 12, n.2, p.406-423, mai./ago. 2017 \\ DOI: http://dx.doi.org/10.7867/1809-0354.2017v12n2p406-423}

BACKHEUSER, E. A aritmética na "Escola Nova": A nova didática da Aritmética. Rio de Janeiro: Livraria Católica, 1933. Disponível em

<https://repositorio.ufsc.br/handle/123456789/134889>. Acesso em: 18 ago. 2016.

BROUGERE, G. A criança e a cultura lúdica. In: KISHIMOTO, T. M. O brincar e suas teorias. São Paulo: Pioneira Thomson Learning, 2002. p. 19-32

CAMPOS, M. F. T. de S. Jogos e materiais concretos em livros didáticos de matemática das séries iniciais do ensino fundamental. 2009. 212 f. Dissertação (Mestrado) - Curso de Educação, Universidade Federal de Minas Gerais, Belo Horizonte, 2009.

CERISARA, A. B. De como o papai do céu, o coelhinho da Páscoa, os anjos e o papai noel foram viver juntos no céu. In: KISHIMOTO, T. M. O brincar e suas teorias. São Paulo: Pioneira Thomson Learning, 2002. p. 123-138

CHOPPIN, A. O historiador e o livro escolar. In: História da Educação. Pelotas. n. 11, abr. 2002. p. 5-24

COSTA, D. A; VALENTE, W. R. O repositório de conteúdo digital nas pesquisas de história da educação matemática. Rev. Iberoam. Patrim. Histórico-Educativo, Campinas (SP), v. 1, n. 1, p. 96-110, jul./dez. 2015.

De PAULA, M. F. B. F. W.. Escola nova em manuais didáticos de Alfredo Miguel Aguayo (Santa Catarina 1942-1949). 2015. 448 f. Dissertação (Mestrado) - Curso de Educação Linha de História e Historiografia da Educação, Universidade do Estado de Santa Catarina, Florianópolis, 2015.

ELKIND, D. Crianças e adolescentes: ensaios interpretativos sobre Jean Piaget. Rio de Janeiro: Zahar editores, 1978.

FERNANDES, J. C. B.; BORGES, R. A. S.. O ensino de primeiro ano primário em tempos de escola ativa: a geometria nos programas brasileiros. Revista Exitus. Santarém - PA Vol. 5 Nº 2 p. 194-213 Jul./Dez. 2015.

GRANDO, R. C. O conhecimento matemático e o uso de jogos na sala de aula. 2000. 224f. Tese (Doutorado em Educação) - Universidade Estadual de Campinas, Campinas, São Paulo, 2000.

GRANDO, R. C. O jogo e a Matemática no contexto da sala de aula. São Paulo: Paulus, 2004.

JULIA, D. A cultura escolar como objeto histórico. Revista Brasileira de História da Educação. Campinas, SP, n. 1, 2001. p. 9-43

KAMII, C. A criança e o número. Campinas, São Paulo: Papirus, 1990.

KISHIMOTO, T. M. O jogo e a educação infantil. São Paulo: Pioneira, 1994. 


\section{Atos de Pesquisa em Educação - ISSN 1809-0354 \\ Blumenau, v. 12, n.2, p.406-423, mai./ago. 2017 \\ DOI: http://dx.doi.org/10.7867/1809-0354.2017v12n2p406-423}

KISHIMOTO, T. M. Jogo, Brinquedo, brincadeira e a educação. 3. ed. São Paulo: Cortez, 1999.

KISHIMOTO, T. M. O brincar e suas teorias. São Paulo: Pioneira Thomson Learning, 2002.

LOURENÇO FILHO, M. B. Introdução ao estudo da escola nova: bases, sistemas e diretrizes da pedagogia contemporânea. São Paulo: Melhoramentos, 1978.

MAGALHÃES, J. M. C. de. Ressignificação de concepções de professores polivalentes sobre sua relação com a matemática e o uso de jogos matemáticos. 2012. 105 f. Dissertação (Mestrado) - Curso de Programa de Pós Graduação em Ensino de Ciências e Matemática, Universidade Luterana do Brasil, Canoas, 2012.

MARQUES, J. A. de O. Manuais pedagógicos e as orientações para o ensino de matemática no curso primário em tempos de Escola Nova. 2013. 131 f. Dissertação (Mestrado) - Universidade Federal de São Paulo, Guarulhos, 2013. Disponível em: <https://repositorio.ufsc.br/handle/123456789/104818>. Acesso em: 05 fev. 2016.

MONARCHA, C.. Brasil arcaico, escola nova: ciência, técnica \& utopia nos anos 1920-1930. São Paulo: Editora UNESP, 2009.

PINTO, N. B.. Matrizes pedagógicas de manuais que ensinam a ensinar aritmética na escola primária em tempos de escola nova: aproximações e distanciamentos. Revista HISTEMAT, ano 2, n. 1. São Paulo: 2016.

SOUZA, T. S de. Entre o ensino ativo e a escola ativa: os métodos de ensino de aritmética dos Grupos Escolares Catarinenses (1910- 1946). 2016. 223f. Dissertação (Mestrado em Educação Científica e Tecnológica). UFSC: Florianópolis, 2016.

TRENTIN, P. H. O livro didático na constituição da prática social do professor de matemática. 2006. 185 p. Dissertação (Mestrado em Educação) — USF, Universidade São Francisco, Itatiba (SP), 2006.

VALENTE, W. R. Livro didático e educação matemática: uma história inseparável. ZETETIKÉ - Cempem - FE - Unicamp - v. 16 - n. 30 - jul./dez. 2008.

VIÑAO FRAGO, A. Sistemas educativos, culturas escolares e reformas. Lisboa: Edições Pedago, 2007.

VYGOTSKI, L. S. Linguagem, desenvolvimento e aprendizagem. São Paulo: Ícone: Universidade de São Paulo, 1988. 